\title{
Teaching
Methods
}

\section{Interactive Online Tools for Teaching Plant Identification}

\author{
Kristin R. Campbell ${ }^{1,4,6}$, Sandra B. Wilson ${ }^{2,5}$, \\ P. Christopher Wilson ${ }^{3,5}$, and Zhenli $\mathrm{He}^{3,5}$
}

\begin{abstract}
ADDITIONAL INDEX WORDS. ornamentals, agricultural education, distance education, active learning, web-technology

SUMMARY. Interactive review exercises were developed as an online learning component of an existing native plant landscaping course. The instruments were designed with specific goals for students to 1 ) test their plant identification knowledge, 2) practice leaf terminology with specific plant examples, and 3 ) associate landscape performance with native ecosystem characteristics. The plant identification tool was developed within a spreadsheet application using formulas consisting of logic statements. This tool tests the students' ability to identify plants and spell scientific and common names associated with high-resolution plant images. The leaf terminology tool was developed using a multimedia platform. It uses a drag-and-drop interface where students are asked to associate a specific leaf term (i.e., margin, apex, base, texture, arrangement) with a scanned image that best matches the taxonomic term. The ecosystem tool, also developed using a multimedia platform, uses digital images captured for each of Florida's major ecosystems in conjunction with sets of plant combinations and site characteristics. Students select the appropriate choices and submit their answers online, after which they receive immediate feedback. Students reported an improvement in plant recognition after they had access to these identification tools. These interactive learning tools not only benefit students enrolled in this specific course but can be adapted to a variety of online courses nationwide.
\end{abstract}

A need for off-campus learning was realized as far back as the 1950s, when increased student enrollment was beginning to limit oncampus space (Curtis, 1957). Today, most campus universities are moving toward distance education as a method for teaching more students with fewer resources (Guri-Rosenbilt, 1999). The results of a recent national survey found over 4.6 million students were enrolled in at least one online course during the Fall 2008 term, a 17\% increase over the previous year (Allen and Seaman, 2010). This by far exceeds the $1.2 \%$ overall growth rate of higher education, showing the trend toward distance education (Allen and Seaman, 2010), in part because of the flexibility offered to students and the elimination of a campus commute (Jeannette and Meyer, 2002). Nearly one-quarter of faculty responding to a recent nationwide survey are reportedly teaching online; over one-third have taught an online course in the past, and the majority of those responding cite the needs of students as the main reason for teaching online (Seaman, 2009).

Within the College of Agriculture and Life Sciences (CALS) at the
University of Florida (UF), a critical emphasis has been placed toward online course transformation in a variety of disciplines including agribusiness, agronomy, environmental horticulture, agricultural communications, entomology, and soil and water science (Rieger et al., 2011). The mission of serving place-bound students throughout the state has significantly increased enrollment while unifying lecture content and minimizing duplication of faculty resources (Wilson and Thetford, 2003). Indicators of quality instruction (with engaged and interactive learning components) parallel with greater student satisfaction (Fredericksen et al., 2000). A recent survey showed that one-half of prospective CALS students located at Research and Education Centers (RECs) prefer some sort of hybrid delivery format, with a mixture of online and face-to-face courses (M. Rieger, unpublished data).

Although numerous studies have shown distance education to be comparable (Anderson and Walker, 2003; Henss et al., 2006; Jeannette and Meyer, 2002; Miller and Pilcher, 2001 ; Spooner et al., 1999) or even superior to traditional classroom teaching (Means et al., 2010), keeping students engaged, motivated, and challenged while teaching online still remains a challenge (Aragon, 2003; Beaudoin, 1990).

Teaching online courses requires the use of a variety of instructional strategies to enhance interactive learning, ensure critical thinking, and provide immediate feedback (Schroeder-Moreno, 2010; Wilson and Danielson, 2003). Many of these are close-sourced materials, not available to other faculty, and only available to students through the respective e-learning site (which is no longer available after the course ends). This project developed a series of innovative plant identification tools for open-sourced, asynchronous applications. These materials can be used by students and faculty worldwide to practice plant identification online.

\section{Interactive identification quiz}

In an effort to incorporate asynchronous student-centered learning exercises into a native landscaping course (ORH3815/5815C), an interactive plant identification quiz was developed using Excel 2007 spreadsheet 
software (Microsoft, Redmond, WA). This quiz allows students to test their ability to identify and spell the scientific and common names of plants taught live in class and to receive immediate responses (correct or incorrect). Six quizzes were developed, one for each course module. On a designated "quiz" tab, high-resolution digital images were inserted into the spreadsheet to use as the basis for scientific name and common name identification (Fig. 1). Users then type their answers into the highlighted cells, which are referenced to the "answer" tab that displays the correct plant name. A single point is awarded for a correct answer for each scientific and common name, and the score is calculated as a percentage of correct answers vs. total answers. By using a logical IF statement, computer coders can modify the program for any given set of plants. If two common names exist for a plant, a second logical statement can be added so that either is accepted. Conditional formatting was used as a visual representation for the user to easily see if the given answer is correct or incorrect. If the student correctly identifies and correctly spells the common or scientific name, the respective cell will highlight in a green color. If the answer supplied is incorrect, the respective cell will highlight in a red color. One of the strengths of these quizzes is that, having been built, they can either be used as is or adapted to new content by anyone who possesses a copy of this spreadsheet software, with no further programming needed. As most computers today are equipped

This project was funded by the UF CALS Mini-Grant Program for instructional improvements of distance education.

Authors gratefully acknowledge Aaron Sotala, IFAS Information and Communication Services, for graphic design and development.

${ }^{1}$ Indian River Research and Education Center, Institute of Food and Agricultural Sciences, University of Florida, 2199 South Rock Road, Fort Pierce, FL 34945

${ }^{2}$ Department of Environmental Horticulture, Indian River Research and Education Center, Institute of Food and Agricultural Sciences, University of Florida, 2199 South Rock Road, Fort Pierce, FL 34945

${ }^{3}$ Department of Soil and Water Science, Indian River Research and Education Center, Institute of Food and Agricultural Sciences, University of Florida, 2199 South Rock Road, Fort Pierce, FL 34945

${ }^{4}$ Graduate Research Assistant

${ }^{5}$ Associate Professor

${ }^{6}$ Corresponding author. E-mail address: gijiweez@ ufl.edu.
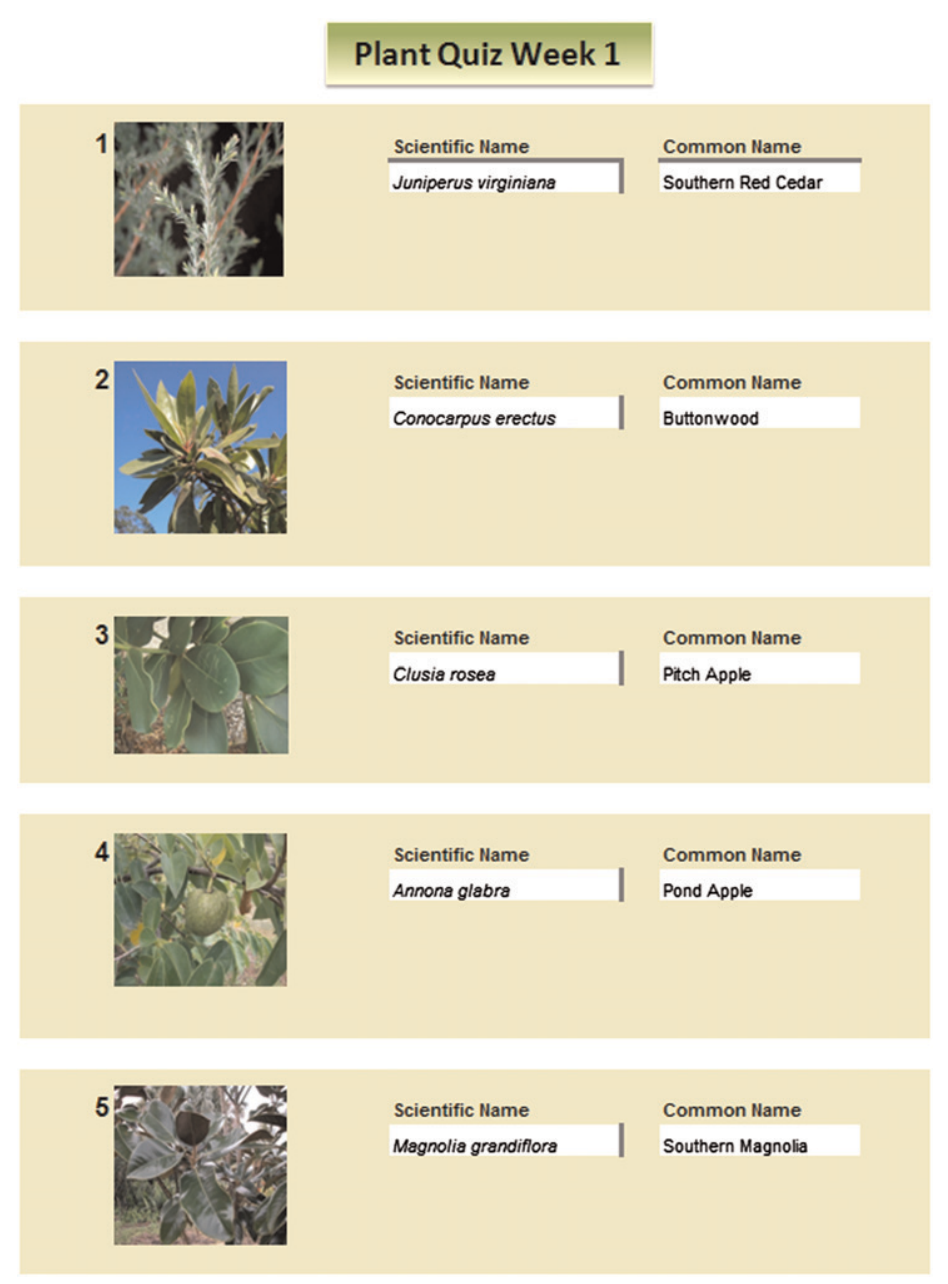

Fig. 1. Screen capture of an interactive plant identification review quiz (Wilson, 2010). Each week users log on to test their knowledge of plant identification by typing out the correct scientific and common names associated with each image. Each spreadsheet has been coded to automatically score the answers and provide an immediate grade.

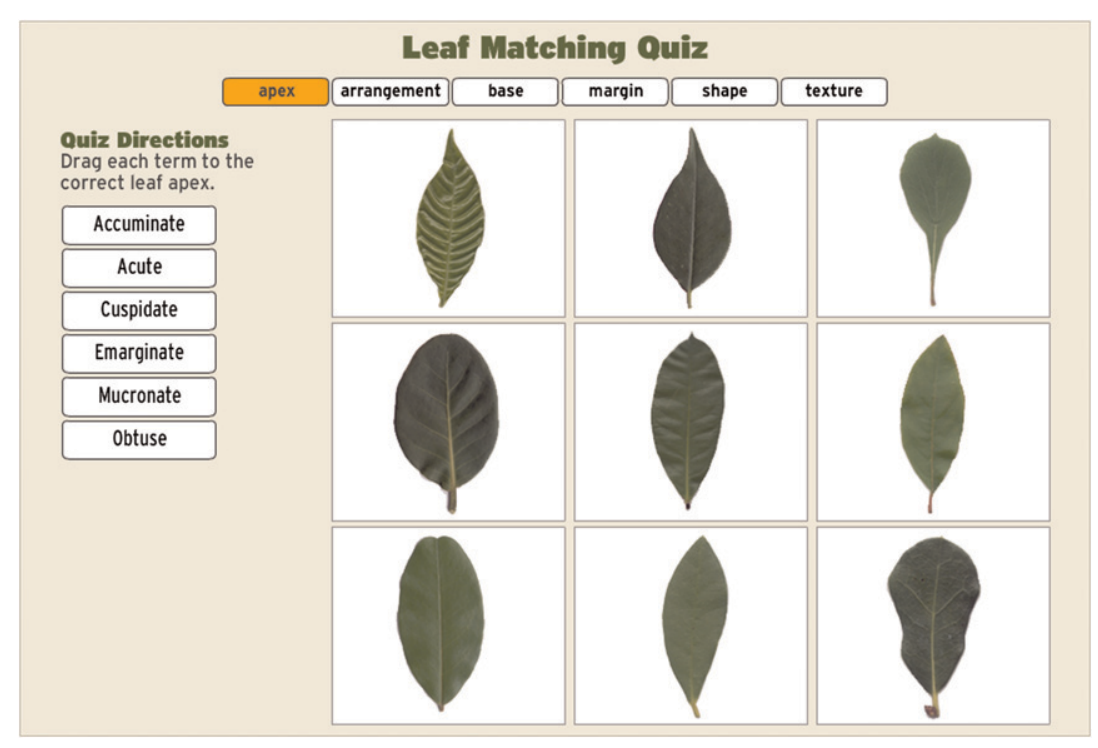

Fig. 2. Screen capture of a leaf properties interactive learning tool (Wilson, 2010). Users log on, select the preferred tab (apex, arrangement, base, margin, shape, texture), and drag a specified term to the corresponding leaf image. 


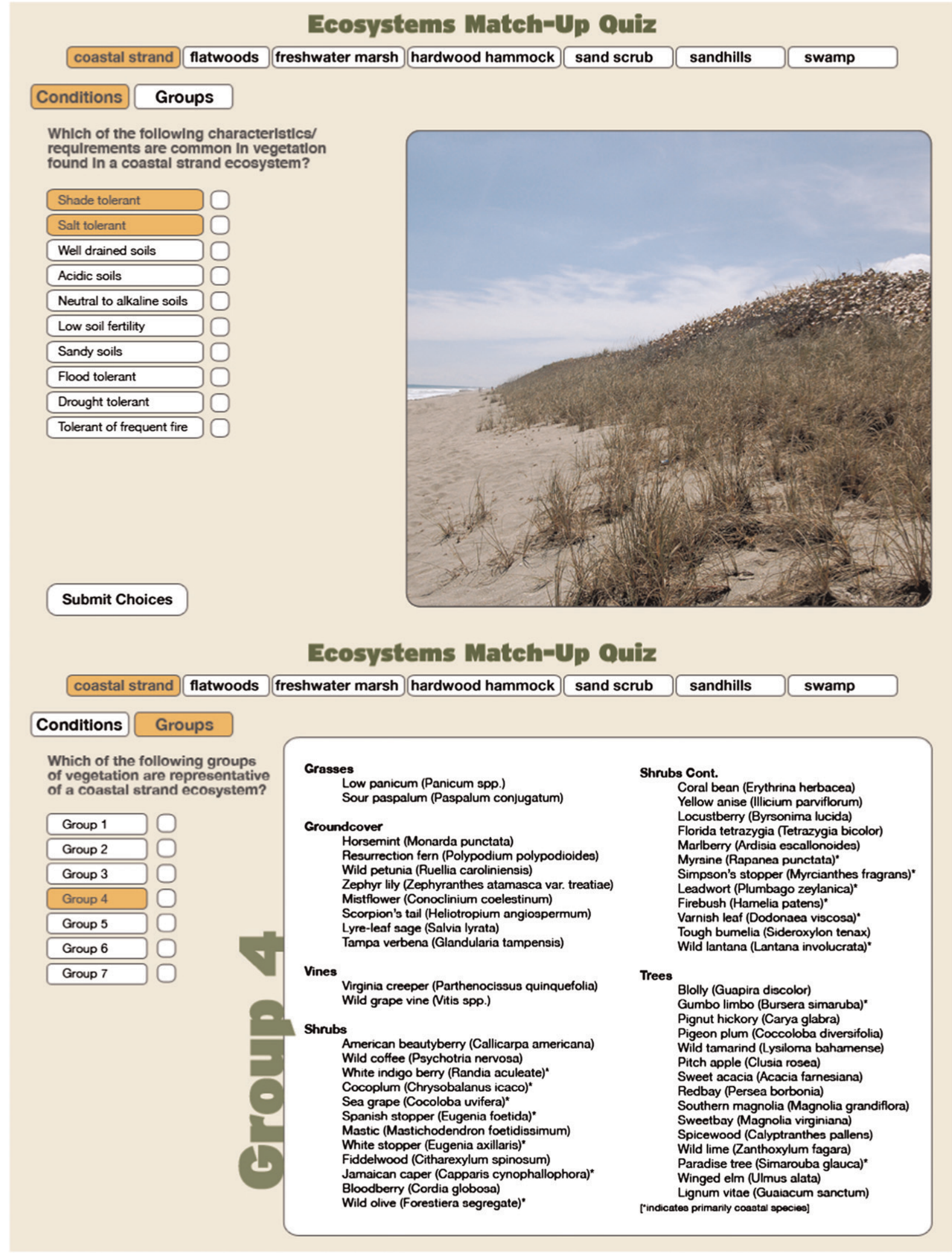

Fig. 3. Screen capture illustrating an ecosystem interactive learning tool (Wilson, 2010). Users log on, select the preferred tab (coastal strand, flatwoods, freshwater marsh, hardwood hammock, sand scrub, sandhills, swamp), click on each site characteristic that is typical of that ecosystem, and then select the appropriate plant group. 
with spreadsheet software, effectively anyone can use the tool to make their own quizzes, thus providing learning impacts that extend far beyond the scope of this single course.

\section{Interactive leaf terminology quiz}

A self-testing tool was built using Adobe Flash CS5 multimedia platform and ActionScript 2 objectorientated language (Adobe Systems, San Jose, CA) as a drag-and-drop quiz to match leaf types with associated terms. These programs were chosen primarily because of their reliability and flexibility for delivering content and for their interactive capabilities for web applications. Native species were selected whose leaves had specific qualities for plant identification (shape, apex, base, margin, arrangement, and texture). All leaves were freshly collected from the UF Indian River REC Teaching Garden (Wilson and Danielson, 2003) and scanned using a color scanner (ScanJet ADF; Hewlett-Packard, Palo Alto, CA) to produce high quality images for the interactive instrument (Fig. 2). The quiz was created by modifying computer codes previously developed for an interactive flash-based jigsaw puzzle and slot machine (UF, Institute of Food and Agricultural Sciences, Information and Communication Services, unpublished data). Existing jigsaw puzzle code was rewritten to allow the leaf terms to be dragged into the grid layout that contained up to nine leaf images. Existing slot machine code was rewritten so a randomization function could be used to reshuffle the leaf order in the grid. This provides users the option of taking the quiz multiple times. Enlarged versions of leaves were added when it was necessary to show greater detail. This was a careful compromise in keeping the project's overall file size manageable. Finally, a feedback message was added to let the user know when they have successfully completed the quiz.

\section{Interactive ecosystem association quiz}

In an effort to associate native plant selection and landscape performance with natural ecosystems, an online learning tool was developed as a review option. This instrument was designed using the same multimedia platform and object-orientated language as the previous quiz, but this time to view a series of ecosystem types, in which users are asked to correctly identify the site characteristics and plant groups that best reflect a given ecosystem. Typical ecosystems throughout the state were visited and high-resolution images of each were captured with a camera (D500; Nikon, Melville, NY). Lists of representative soil properties (drainage, organic matter, moisture, salinity), environmental conditions (wind, sun, shade), and plant species (indigenous grasses, vines, shrubs, trees) were compiled for each of the seven major ecosystems of Florida (sand scrub, sandhills, flatwoods, marsh, swamp, coastal strand, and hammock) (Schaefer and Tanner, 1997). The web interface consists of a series of tabs labeled by ecosystem (Fig. 3). When users select a particular ecosystem tab, an image of that respective ecosystem appears. Users then have the choice to select a sub-tab labeled "conditions" or "groups." When the "conditions" tab is selected, users are asked to control which of the listed characteristics or requirements are common to the vegetation found in that ecosystem. After submitting their choices, users are then asked to select the group of plants likely to be found in that particular ecosystem. These tools have the ability of being expanded even further with other multimedia and interactive capabilities, should there be a need.

In summary, three new instruments have been developed to facilitate online learning. Although originally designed for a native landscaping course, these applications can be easily modified for numerous other horticulture courses. These tools are opensourced and available worldwide, in which content can be modified accordingly. The Interactive Identification Quizzes are especially versatile, with the flexibility of being used by anyone who adapts the formulas for any series of plants with the provided coding. For educational purposes, original plant images and all the online applications may be used or downloaded from the course website (Wilson, 2010).

\section{Literature cited}

Allen, I.E. and J. Seaman. 2010. Learning on demand: Online education in the
United States, 2009. Babson Survey Research Group, Babson Park, MA.

Anderson, N.O. and J.D. Walker. 2003. Effectiveness of web-based versus live plant identification. HortTechnology 13: 199-205.

Aragon, S.R. 2003. Facilitating learning in online environments. Jossey-Bass, San Francisco.

Beaudoin, M. 1990. The instructor's changing role in distance education. Am. J. Distance Educ. 4:21-29.

Curtis, D.K. (ed.). 1957. Achieving quality in off-campus professional laboratory experiences. Iowa State Teachers College, Cedar Falls, IA.

Fredericksen, E., A. Pickett, P. Shea, W. Pelz, and K. Swan. 2000. Student satisfaction and perceived learning with online courses: Principles and examples from the SUNY Learning Network. J. Asynchronous Learning Networks 4(2):1-41. 26 May 2011. <http://sloanconsortium. org/jaln/v4n2/student-satisfaction-andperceived-learning-line-courses-principlesand-examples-suny-lear>.

Guri-Rosenbilt, S. 1999. Distance and campus universities: Tensions and interactions: A comprehensive study of five countries. Elsevier Science, New York.

Henss, S.R., J.M. Zajicek, and R.D. Lineberger. 2006. A comparison of student grades, floral design laboratory skill scores, and course satisfaction of traditional and online sections of a university floral design course. HortTechnology 16: 626-632.

Jeannette, K.L. and M.H. Meyer. 2002. Online learning equals traditional classroom training for Master Gardeners. HortTechnology 12:148-156.

Means, B., Y. Toyama, R. Murphy, M. Bakia, and K. Jones. 2010. Evaluation of evidence-based practices in online learning: A meta-analysis and review of online learning studies. U.S. Dept. Educ., Washington, DC.

Miller, G. and C.L. Pilcher. 2001. Levels of cognition reached in agricultural distance education courses in comparison to on-campus courses and to faculty perceptions concerning an appropriate level. J. Agr. Educ. 42:21-28.

Rieger, M., R.E. Turner, and R.K. Barrick. 2011. Student evaluation scores for courses delivered by interactive videoconferencing. North Amer. Colleges Teachers Agr. J. In press.

Schaefer, J. and G. Tanner. 1997. Landscaping for Florida's wildlife: Re-creating native ecosystems in your yard. University Press of Florida, Gainesville, FL. 
Teaching Methods

Schroeder-Moreno, M.S. 2010. Enhancing active and interactive learning online- Lessons learned from an online introductory agroecology course. North Amer. Colleges Teachers Agr. J. 54:21-30.

Seaman, J. 2009. Online learning as a strategic asset, Vol. II: The paradox of faculty voices: Views and experiences with online learning. Assn. Public and Land-grant Univ., Washington, DC.
Spooner, F., L. Jordan, B. Algozzine, and M. Spooner. 1999. Student ratings of instruction in distance learning and on-campus classes. J. Educ. Res. 92:132-140.

Wilson, S.B. 2010. Florida native landscaping review materials. 3 Mar. 2011 $<$ http://irrecenvhort.ifas.ufl.edu/FNL/ review.html>.
Wilson, S.B. and H.E. Danielson. 2003. A new instrument for interactive virtual plant identification and use. HortTechnology 13:1-2.

Wilson, S.B. and M. Thetford. 2003. A new strategy for teaching plant propagation by distance education. HortTechnology 13:577-578. 